\title{
Empowering women through the positive birth movement
}

\section{Abstract}

Childbirth has been positioned as a life changing event that has profound long term psychological effects upon women. This paper adopts a community psychology approach to explore the role that the Positive Birth Movement (PBM may have in tackling negative birth experiences by supporting women before and after birth. Six women who all regularly attend UK based Positive Birth Movement meetings and had given birth to at least one child participated in one to one semi-structured interviews designed to explore the support they received before, during and after their birth, as well as their experiences with the positive birth movement. A Foucauldian inspired discourse analysis explores themes relating to the lack of support and information provided by the NHS and the function of the positive birth movement as a transformative community space which offers social support and information. Within these themes a focus on neoliberalism, choice and the woman's position as an active consumer of health care is critically discussed. It is argued that the PBM has the potential to prepare women for positive birth experiences but more attention needs to be paid to the wider contexts that limit women's ability to make 'free' choice.

\section{Keywords}

Community action, health psychology, birth, Foucauldian Discourse Analysis. 


\section{Introduction}

Childbirth has been described as an 'intense, powerful life experience'

(Halldorsdottir \& Karlsdottir, 1996, p. 56) which has long term psychological outcomes for women (Simkin, 1992). Positive birth experiences have been linked to feelings of empowerment (Lundgen, 2005) whereas negative birth experiences have been associated with feelings of guilt, violation and depression (Bailham \& Joseph, 2003). It also has been reported that births resulting in post-traumatic stress disorder have a long term negative impact upon family dynamics (Ayers, Eagle \& Waring, 2006). These findings are significant as, according to recent figures, 20,000 British women suffered from PTSD and an estimated 200,000 suffered from birth related trauma (Birth Trauma Association, 2018).

The effect of women's expectations of childbirth has been examined in relation to their birth experiences and emotional well-being afterwards. Green, Coupland and Kitzinger (1990) reported that women who had positive expectations about their birth went on to experience feelings of control over the birth experience which led to feelings of satisfaction. Negative expectations about birth led to less fulfilling birth experiences and negatively impacted on women's wellbeing. This indicates that working with women throughout pregnancy to set expectations about their birth experience could be a way of tackling birth trauma. In order to explore this further the current paper focuses specifically on a UK based positive birth movement (PBM) group. A specific concern is to explore the ways in which this group works with women during and after pregnancy in order to offer social support and address birth trauma. The paper will address this aim by first reviewing relevant literature which attends to the contexts which shape birth experiences within the UK and the positive 
birth movement itself. The experiences reported by women as part of a community psychology project are investigated using FDA. This methodology allows the community to play an active role in the research process and move away from the individualist approach traditionally adopted within psychological research.

\section{Conceptualising birth within a Western context}

Within a Western culture there is not always a straightforward relationship between women's expectations of and their lived experience of birth. Malacrida and Boulton (2014) argue that women's experiences of pregnancy and birth are shaped by three dominant positions - medical, natural birth advocacy and feminist.

A medical approach positions the pregnant woman as a patient whose pregnancy and labour needs to be managed by medical staff. Hospitals are conceptualised as the safest place to give birth and this establishes an unequal power dynamic in which the pregnant woman has limited control over her birth experience and interventions recommended by medical staff (Brubaker \& Dillaway, 2009).

The natural birth advocacy movement stresses the woman's natural capacity for birth and an intervention free home birth is considered to be the gold standard (Cheyney, 2008). Women are encouraged to use methods such as hypnotherapy and write birth plans, which outline the levels of medical involvement considered to be acceptable, to maximise their chances of an intervention free birth (Malacrida \& Boulton, 2014).

A feminist approach questions the medicalisation of birth and the lack of control this affords women over their birthing body (Kukla, 2005). However, this approach also 
questions the romanticisation of natural childbirth and the pressure for women to give birth naturally (Beckett, 2005). Within a feminist framework it is acknowledged that women's ability to make 'real' choices is limited by the medical and birth advocacy approaches they are situated within (Malacrida \& Boulton, 2014). This is evidenced in Crossley's (2007) auto-ethnographic account which detailed how her expectations of natural births were not matched by her experiences due to medical intervention, leaving her with a sense of failure. Malacrida and Boulton's (2014) findings support this on a larger scale by demonstrating a discrepancy between expectations of a natural birth and medicalised experiences.

\section{Managing expectations of birth}

In the UK women receive information on pregnancy and birth from the National Health Service (NHS). The NHS offers all women a course of antenatal classes which address issues surrounding what to expect during labour and information relevant to new parents. Pregnant women are also expected to attend regular check-ups with midwifes which monitor the progression of the pregnancy with the aim of early identification of medical issues. As part of this women are offered ultra sound scans during weeks 12 and 20 of their pregnancy and when considered necessary other antenatal screening tests. If, as a result of this monitoring, the pregnant woman is considered to be high risk then she is referred to consultants for more specialised, hospital based medical support. Consequently, the 'official' advice routinely offered to women during their pregnancy is shaped through a medical gaze.

When preparing for birth some women choose to seek out information from sources outside of the NHS. The media, and how it reports issues surrounding pregnancy and 
risk, is one key source of information. Information presented in newspapers, magazine and TV works alongside medical knowledge sites to communicate what is means to be a 'good mother' and sets the perimeters for acceptable behaviour for pregnant women (Gross \& Pattison, 2007). Pregnant women are expected to follow advice promoted from these outlets concerning issues such as diet, alcohol consumption and exercise or face judgement as a selfish and irresponsible mother with little concern for the health of her baby.

Social networking sites have recently played an important role in providing women with information and support. A number of groups such as 'home birth group' now have a social media presence. Such groups largely conform to a natural birth advocacy approach and offer an alternative to medicalised model predominant within NHS settings and the media. Access to these knowledge sites potentially feeds into Elston's (1991) observation of move towards the demystification of expert knowledge, reduction of professional control and suspicion of doctors.

A community approach to birth

The Positive Birth Movement (PBM) is a community group established by Milli Hill in 2012 , originating from the UK, with the aim of informing women of their birth choices, sharing birth stories and offering support for women during and after their pregnancy. The group is a non-profit organisation and all pregnant women and mothers are invited to attend regular meetings held in their local area free of charge. PBM meetings centre on a specific discussion topic and are led by facilitators who come from a wide range of backgrounds; some are doulas (people who offer support during pregnancy and before and after birth) and midwives whereas others are 
women who are passionate about birth and want to offer support. Within 18 months of the PBM starting, 130 regional groups were established within the UK and a number of groups had been set up worldwide in countries including Canada, Africa Poland and Australia.

The PBM positions itself as a community based grass roots organisation which aims to (i) support and empower pregnant women through information and authentic birth stories, (ii) provide a supportive social network to 'new' mothers and, (ii) offer women who have suffered birth trauma or have had negative birth experiences a 'safe space' to discuss their experience and work through their feelings. Within meetings, a positive birth is conceptualised as any birth (from a home birth to a caesarean) in which the woman felt empowered through access to information and freedom of choice. As demonstrated by Cipolletta and Sperotto (2012) a good birth is subjective. For some women a low intervention birth is conceptualised as positive whereas for others handing over control to a healthcare professionals results in a positive birth experience. This is reflected within the PBM (2018) conceptualising a positive birth as one in which "women are where they want to be, choices are informed by reality not fear, women are listened to and treated with respect and dignity, mothers are empowered and enriched and memories are warm and proud".

Within the PBM it is also acknowledged that not all birth experiences are empowering and many women suffer birth trauma. Indeed, women often come to the PBM as the result of a negative first birth and a desire for a more positive second 
birth. Women are invited to share both negative and positive birth stories in a space which emphasises support.

A focus on 'choice' means that the PBM sits outside of the three established discursive economies surrounding birth (medical, natural and feminist). Instead, birth is constructed within a neoliberalist rationality where humans are understood as economic beings or 'homo economicus' (Foucault, 2008). Within this 'regime of truth' the construct of the free economic market is naturalised and applied to the social realm as people are positioned as rational decision makers who govern themselves through self-interest and competition (Oksala, 2013). People are therefore conceptualised as entrepreneurs of the self who actively invest in themselves through their choices and actions, so success and failure are reducible to an individual level (Read, 2009). When applied to the PBM, women are positioned as active agents who take responsibility for their birthing choices based on an 'informed choice' of what would benefit them.

This reflects a boarder trend reported by Gross and Pattison $(2007$, p. 13) in which women are 'taking more responsibility for their health and adopting more consumerist attitudes to healthcare'. Creation of what Beck (1992) terms 'risk society' points towards a paradox relating to expert knowledge. Medical advances have improved care for pregnant women and babies thus reducing mortality rates, increasing knowledge around risk factors and also bringing a sense of control over pregnancy and birth. However, this is coupled with a growing distrust of scientific knowledge and movement towards personal agency and self-management of risk (Gross \& Pattison, 2007). Within this self-care culture, beliefs that nature will take its course have been replaced by narratives of personal responsibility in which 
women are active agents who have access to the information required for them to make informed decisions over what happens to them and their baby during pregnancy and birth. Thereby positioning women as 'instrumental in a successful problem free pregnancy' (Gross and Pattison, 2007, p. 2). It is left to the mother to effectively use the information provided to her through a number of sources to make informed decisions for themselves and their babies, and, by implication, be accountable for the 'choices' that are made within this neoliberal framework (Locke \& Budds, 2013).

\section{Aims of the current research}

The current paper adopts a community psychology approach to explore the role that the PBM can have in supporting women and investigate the women's experiences of the group and what it has to offer them. A community psychology approach compliments the aims of the PBM because it positions the birthing experience within the wider social context and situates the analysis in terms of social and power relations rather than focusing at an individual level (Prilleltensky \& Nelson, 1997). The research is action orientated, members of a community become the experts in identifying issues and power inequalities and become agents for social change (Rappaport \& Stewart, 1997). This shift in power relations means the researcher becomes a resource collaborator who works with a community as opposed to working on them (Smith, 1994).

The first and second authors became aware of the PBM shortly after the birth of their first child in 2012. Discussions with their local PBM facilitator (and fourth author) led to a research partnership being developed. The project started with a 
meeting between the first, second and fourth authors in which the fourth author took the lead in discussing what she, and the PBM group, wanted to achieve through the research. The fourth author had two main objectives (i) to build an evidence base that could be presented to the local midwifery service and (ii) explore what brought the women to the group and the potential benefits and challenges the PBM presented. Such information was considered key to bringing about further positive change as it would enable the PBM group to establish a dialogue with their local midwifery service and help the group understand how they might reach out to women who belong to disadvantaged communities.

\section{Method}

\section{Recruitment procedure and participants}

The first and second authors worked with the fourth author to develop an interview schedule and trained the fourth author in research ethics and interviewing techniques. The fourth author then recruited participants by posting information about the project and what participation involved on the PBM social networking site. Six women responded to the social network post and took part in one to one semistructured interviews facilitated by the fourth author. The interview schedule invited the women to discuss their birth experience(s), the support they received before, during and after their birth(s) and their experiences with the PBM and what prompted them to join. All interviews took place between December 2013 and February 2014, were between an hour and two hours in length and were transcribed verbatim for analysis. The study conformed to the British Psychological Society (2009) ethical standards. 
The women who participated in the research enabled a range of birth experiences and involvement with the PBM to be captured. Sarah, Harriette, Jessica and Vicky had expressed interest in low intervention births during their first pregnancies and felt disappointed that they were admitted to hospital and went on to have a more medicalised birth than they had hoped for. They joined the PBM after this first experience and then went on to have home births or low intervention second births in a birth centre. For these women the PBM had been a source of support and an arena where they could share their experiences of hospital and home births. Teresa had a positive hospital birth and joined the group to share her story and access information relevant to her second pregnancy. Alison had delivered both her children through emergency caesarean and suffered birth trauma through both of these deliveries. She came to the group to gain support and work through her feelings towards her birth experiences.

The sample reflects the membership of the specific PBM group involved in this research. Although the group is open to all women typically, it is middle class women who predominantly attend the group. The membership of the group reflects wider societal norms in which middle class mothers are more likely to seek out information and support regarding birth (Gillies, 2007). All women are welcome in PBM meetings but, as mentioned previously, the group are actively working to reach out to disadvantaged communities in an effort to widen out the support they offer. 


\section{Analytic approach and procedure}

The interviews were viewed as one data corpus and analysed using Foucauldian inspired discourse analysis (FDA) which operates at a macro level to explore the ways in which wider social, historical and cultural contexts shape our experiences. Broadly speaking, FDA is consistent with a social constructionist epistemology, which assumes knowledge is relative to a context and produced through human activity and relationships as opposed to being trans-historical, neutral, value free and universal (Gergen, 2015).

Within a FDA approach three key concepts are central to analysis - discourse, subject position and power. Discourses embody commonplace knowledge and "established truths" that are accepted within a particular society (Graham, 2005). Therefore, discourses are organised systems of meaning specific to a particular historical and cultural context which establish what is normal within any given society (Hook, 2001). When considering discourses Foucault suggested that "living persons are required to 'take up' subject positions in discourse in order to make sense of the world and to appear coherent to others" (Barker \& Galinski, 2001 p. 13). When someone takes up a subject position such as patient, mother, doctor and midwife they personify the discourses that create that subject position. Consequently, subject positions are linked to power because they categorise individuals by enabling and constraining what can be said or done (Davies \& Harré, 1990). Some subject positions are more powerful than others and this creates boundaries between those that can dominate and those who can be dominated (Graham, 2005). 
Foucault himself did not propose an explicit model of conducting an analysis (Graham, 2005). Therefore within this project, the six stages of thematic analysis outlined by Braun and Clarke (2006) provided a useful framework to organise the data set and identify key themes which could be subjected to a FDA analysis. The analytic procedure started with immersion in the interview data. Analytic notes made during this process were used to code the data and extracts relating to each code were collated to ensure there was enough textual evidence to support them. Codes with a common link were grouped together to form themes. Extracts from the interviews which best represented each theme were then selected and analysed using FDA principles. More specifically, discourses, subject positions and power were attended to and examined. At this point the second, third and fourth authors reviewed the extracts and analysis to ensure rigour and representativeness.

\section{Analysis}

This analysis explores women's experiences during pregnancy and the role of the positive birth movement.

\section{Experiences during pregnancy}

All of the women interviewed went through their first birth experience without the support of the PBM. This theme explores the support women received during their first pregnancy.

Searching for information

A common issue amongst the women related to a quest for information.

"I had a midwife who erm, was obviously with the NHS, who was reasonably 
supportive. I wouldn't say overly supportive, she was always, how can I say it, she was always quite communicative at every appointment. It wasn't just a matter of filling in forms etcetera erm, and she advised me on my choices really, through what options I had in terms of hospital birth or home birth." Teresa

Throughout this extract a neoliberalist discourse centering on personal choice is central to constructing good support from a midwife. The presentation of advice and the discussion of birthing options positions Teresa as an active agent who is able to take the information provided by the midwife to make informed decisions relating to her birth experience. This disrupts traditional power relations present within a medical discourse which position healthcare providers as a source of unquestionable authority responsible for making decisions on behalf of their patient. Indeed, Teresa goes on to problematise the practice of filling in forms. This type of communication embodies traditional power dynamics and places the pregnant woman in a passive position from which she is expected to answer questions directed by the midwife. The information gathered is then used to inform decisions surrounding the pregnant woman's care. However, Teresa's position as an active agent who is able play a central role in key decisions surrounding her birthing environment is tempered by her suggestion that the midwife was not overly supportive and was quite communicative. This positions the midwife as a healthcare professional who did not fully enable Teresa to access the information she required. 
This is further explored below. Alison, like many of the other women interviewed, was dissatisfied by the information provided by the NHS and therefore sought out information from different sources.

"I did all the research erm, I read books. I had a friend who leant me a book that kind of started it snowballing, I got a doula, I got more books, I found online support erm, yeah, that's I did it all myself."

\section{Alison}

Repeated use of the word 'I' emphasises personal agency and locates Alison's experience of a lone search for information within a neoliberalist discourse. In a culture of self-care, Alison is positioned as a 'good mother' who actively seeks out information relating to pregnancy and birth without the support of healthcare professionals. Consequently, she is personally responsible for sourcing information which will help her have a healthy pregnancy and inform her birth choices. When listing her information sources Alison makes reference to a doula. This suggests that the information she received from her midwife was inadequate and also highlights the privilege that her social class has to offer. Alison had the funds required to employ someone with specialised knowledge to offer her personalised support during pregnancy. This creates a two tier system where women with a disposable income are able to buy in support and access the information they seek but those without such resources are left by the NHS to fend for themselves. Access to material resources can therefore widen the choices available and demonstrates that 
'choice' cannot be reduced to an individual level based on rational decision making as understood within a neoliberalist discourse.

"You shouldn't have to work so hard to get that information and like I say I appreciate the midwives don't have all the time in the world and they don't, they don't have every resource in the world but even if they can just signpost you to places where I could've got that information, you know" Vicky

Not all of the women positioned themselves as people who were able to access the information they needed during their pregnancy. Throughout this extract a medical discourse positions midwives as gatekeepers who have the power to signpost women to specialised knowledge concerning childbirth. Use of the word could've and a switch to the past tense indicates that Vicky did not receive the support she needed in finding information during her pregnancy. This positions the midwife as an unsupportive healthcare professional who maintained traditional power relationships through withholding knowledge as an 'expert'. It also further highlights issues faced by women who do not have the money to fund personalised support or women who are not linked in to a supportive network. 
A focus on negative aspects of birth

When conducting their research into birth many of the women reported an emphasis on negative birth experiences in the information they found.

"I've talked to women before and I had my baby and oh, it was awful and they were quite happy to just, they wanted to terrify me, you know, it was one of those. I remember thinking oh my goodness "

Alison

Alison highlights the normalisation of birth narratives surrounding fear and the positioning of women's bodies as weak and unable to cope with the demands of birth. This feeds into medical discourses which conceptualises the female body as faulty and in need of intervention. Therefore, Alison is positioned within a community which undermines natural birth discourses and the presentation of birth as a natural event that is to be embraced. Tension between natural birth advocacy discourses and medical discourses was further unpacked by Jessica in her interview.

"I think there's too much negativity surrounding pregnancy and birth in the media and within our society I think there's a lot of assumptions made that are taken as the norm which need to be dispelled so that most women have positive birth experiences, instead of just a few." Jessica 
Negativity surrounding childbirth are conceptualised as a barrier to positive birth experiences. Thus, medical discourses popularised by the media are aligned with an undesirable status quo in which only a few women have positive birth experiences. The promotion of birth stories, which stress the body's natural capacity for birth, are presented as key to enabling most women to have good birth experiences. The presentation of two extremes - few and most - serves to maximise the impact that positive birth stories can have in transforming women's birth experiences.

A focus on negative aspects of birth was not just present in the media and in other women's birth stories. Below Sarah discusses the role they played in a privately run antenatal classes.

"The antenatal care provider was very focussed on pain relief options and what can go wrong. They didn't want to kind of, they were supportive about birth plans but they said but it will probably change on the day, you know."

\section{Sarah}

At the beginning of this extract medical discourses shape the way that Sarah conceptualises her antenatal care provider. Emphasis on complications and uncertainty construct the pregnant woman's body as unreliable and therefore in need of medical assistance. However, in the second part of the extract feminist discourses draw out issues of power and point towards the 'illusion of choice' women experience when planning their birth experience. The suggestion that birth plans ... will probably change on the day undermines a neoliberalist approach to 
birth. In a medicalised context woman are subjected to unequal power dynamics and are not free to make any choices they wish. The wider context is presented as being central to shaping the woman's experience.

This section of the analysis highlights the importance of the wider social contexts in which pregnancy is situated and the role these contexts have in shaping women's pregnancy and expectations of birth. External agencies such as the NHS, private antenatal providers, other mothers and the media were all aligned with medical discourses which promoted fear and set expectations of a negative birth. In contrast, good support and information were located within neoliberal discourses which enabled the women to make informed decisions surrounding their pregnancy and birth. Positioning of the women within a neoliberalist discourse created a context in which information surrounding birth accessed by the women was constructed as harmful. An important exception was identified in Alison's discussion of a doula. This draws attention to the role of social class and the way in which access to material resources enables some women to buy in specialised birth support and the choices this offers.

\section{The role of the positive birth movement (PBM)}

This final theme explores the women's experiences of the positive birth movement.

\section{Providing support}

Many of the women spoke about how the meetings they attended offered them a valuable form of social support.

"I think it's been lovely to meet like-minded people, to meet people who've had 
positive birth experiences, you know, that have been really different from mine, but still really positive and I think it's always nice to share these experiences. It gives hope to other women, I think it's been really lovely when there've been pregnant women in the group who haven't had babies before or who are having second or third babies and want a more positive experience, I think that's fantastic. It's a brilliant social group as well as a support group for me and for lots of women who l've met." Jessica

Discourses surrounding empowerment shape Jessica's presentation of the PBM meetings as a space that transforms women's expectations of birth. This shifts away from the neoliberalist discourses present in the first theme and emphasis lies in social support and the sharing of really different positive birth experiences. Absence of medical and natural birth advocacy discourses indicates that a variety of birth experiences are presented as positive and the focus is on sharing a range of authentic birth stories. Jessica's presentation of PBM meetings as a community space positons then as a better alternative support provided by the NHS in two ways. First, it positions pregnancy as a journey shared by other women rather than an individual experience. This stands in stark contrast to the lone search for information presented in the first theme and situates the women within a transformative community. Second, the group is conceptualised as a space in which women can gain access to the information they require from like-minded people. Consequently, PBM 
meetings are constructed as a space which offers an alternative to narratives surrounding fear explored in the first theme.

"My mum, she ended up with an emergency caesarean in the end erm and you know she did have a tough time and I think maybe had, and I know we're going back thirty two years now but had she of been able to come to a group, get the support, let go, have a chat, work out, you know what was positive about it maybe she'd feel very differently about that experience." Vicky

A therapeutic discourse conceptualises PBM meetings as a place in which women who have had a tough birth are able to share their experiences and work through birth trauma. Engaging in dialogue with other women is presented as the key to reconceptualising their negative experience of the birth.

\section{Providing information}

The PBM was also conceptualised as a place where women could access and share information.

"Even if sharing my story can just make a few other women just think or reconsider their own options and hopefully have a better outcome from it. I feel like I've achieved something erm, and I, you know, I've really enjoyed the group erm, and yeah, just like I say being able to educate, I suppose educate 
is a very strong word, but just to show there that experience and those

options. Yeah, so I've really enjoyed it. "

Vicky

Throughout this extract empowerment is conceptualised though a neoliberalist discourse which positions Vicky as an expert who is able to educate others about their birthing options. Vicky's position and the presentation of PBM meetings as an informative space which centre on exploring birth options disrupts traditional power relations created by a medical discourse. Information enables movement from the passive position of patient towards a more powerful position from which women are able to make informed decisions about their birth. Significantly, the women themselves are presented as the key to bringing about change and are positioned as experts in managing their own risk. PBM meetings are conceptualised as a place where women invest in themselves to facilitate both personal and collective empowerment.

"Yes I like the fact that people post articles that I can choose to read if I like but if I don't want to read it I don't have to read it and then once I've read it I can share it with other people. I think it's an excellent way of spreading relevant information. That you can access things and tag people knowing again, if they want to read it they can and if they don't they don't have to. I think it's revolutionised documentation, it's brilliant for this sort of thing." 
Jessica

Jessica discusses how the PBM social networking page enables members of the group to actively share and access information. This collective action further disrupts power relations created within a medical discourse. More specifically, sharing information challenges the midwife's position as gatekeeper. As previously discussed midwives were positioned as healthcare professionals who did not signpost women to relevant information and therefore left pregnant women unsupported. In direct contrast to this the PBM social networking site is presented as a place in which women work together to demystify medical knowledge and provide social support.

For many of the women access to information was important as knowledge led to power and control over their birth experience.

"I mean you must feel this as the leader of it, when, when someone says, 'oh, my god, so I can say no to that?' And you're like, 'oh yes! You can! Say no to it, you don't have to do it'. And it's, it's quite, it must feel absolutely daunting for them. 'Cos I guess for me, my, all my research and my confidence in saying no has built up over 4 years between Rowan's birth and my impending second birth." Harriette 
A neoliberalist discourse shapes Harriette's presentation of the PBM as a group that educates women about their rights during pregnancy and labour. Within the narrative active voicing is used to demonstrate how the PBM works to disrupt traditional power relations. However, Harriette's assertion that so I can say no to that? indicates that this repositioning within a medical context is not easy. It requires the pregnant women to adopt the position of an expert in managing her own risk. Within Harriette's account research is connected with the confidence to say no and therefore the ability to draw upon an evidence base is central to adopting a position of control. This is further explored by Jessica below.

"It's the same I think with midwives and doctors, I know I haven't had any complications to contend with but little things like when my, the blood tests came back with my iron being quite low, and that's something that they flag up as an issue for possibly not having a home birth. I found that because I had read about it and I said that I know that this is not that low, I am eating a lot of iron-rich foods, I don't want to take those horrible iron tablets that make everything so much worse, I felt that they backed off a bit because I was informed and I wasn't just going to be told what I needed to do." Jessica 
Jessica explores a tension between medical discourses and natural birth advocacy discourses. Doctors and midwives are positioned within a medical discourse as experts who have the power to block Jessica's request for a home birth on medical grounds. However, Jessica situates herself within this medical discourse and asserts knowledge of her condition, positions herself as someone taking positive action and demonstrates her understanding of the side effects of a recommended course of action. Therefore, access to information from the PBM was key to repositioning Jessica as a competent woman able to understand and manage risk. This in turn enabled Jessica's pregnancy and birth to be reconceptualised within a natural birth advocacy discourse.

This section of analysis further highlights the role of the wider context in shaping women's birth experiences. PBM meetings were constructed as a transformative space which empowered women through social support and access to information. A focus on social support presented PBM meetings as an antidote to the lack of social support provided by the NHS. Sharing birth stories in a supportive space opened the women up to different birth experiences and narratives which served as a welcome alternative to the fear driven accounts presented in mainstream sources. Furthermore, a neoliberalist discourse conceptualised information shared through PBM meetings and social media as central to enabling personal choice and key to challenging unwanted medical attention. 


\section{Discussion}

The current analysis has raised important considerations in relation to the wider contexts which shape women's experiences of pregnancy and birth. When discussing experiences outside of the PBM a neoliberalist discourse largely positioned the women as 'good mothers' who were actively seeking information about best practice in order to make informed choices for themselves and their babies. From this position dominance of medicalised discourses surrounding birth were rejected because they questioned women's natural ability to birth and set expectations for a negative birth experience. Within this discourse healthcare professionals were conceptualised as 'experts' who limited women's access to information and left pregnant women to access the information they required alone. Given the link between negative expectations of birth and birth trauma reported by Green et al (1990) this is noteworthy. It suggests that expert and popular sources of information available to the women feed into negative birth experiences which impact upon women's wellbeing.

More broadly, the women's positioning within a neoliberalist discourse feeds into a self-care culture reported by Gross and Pattinson (2007) in which women are conceptualised as rational decision makers responsible for their wellbeing. A middle class identity played an integral role in making the position of an active consumer of available healthcare. This draws attention to the role that material wealth has in shaping access to support either through the employment of a doula or having the time and resources to purchase books providing information about pregnancy and birth. It also indicates that women who do not have such a privileged position are 
left to fend for themselves in a society that promotes fearful messages about birth with little support from healthcare professionals.

In contrast, PBM meetings were conceptualised as a transformative space which enabled women to gain access to a supportive community, information and authentic birth stories. Community action was positioned as key to preparing women for a positive birth experiences and disrupting traditional power dynamics within a medical model. As demonstrated in the analysis a neoliberalist discourse and focus on empowerment repositioned women as experts and enabled them to challenge and successfully reject unwanted medical attention. This indicates that the kinds of support offered by the PBM can tackle birth trauma by setting expectations for a positive birth and also providing women with the information needed to provide a sense of control. Furthermore, the PBM's decision not to charge for attending groups and provision of free access to social media pages works to enable women with limited material resources to access information and support.

It is important to note that the neoliberalist discourse overall positions responsibility as an individual choice rather than understanding it within a wider set of complex social, historical, material and political relations. As already discussed 'choices' made outside of the PBM, particularly in relation to employing a doula, required access to material resources that were not free or accessible to all pregnant women. Similarly, no matter how well informed a woman is there are situations in which actively resisting medical advice positions her as a reckless mother who requires intervention (Lupton, 2012). Medical staff are therefore able to take over and sometimes make decisions or follow a course of action which goes directly against 
the pregnant woman's wishes (Malacrida \& Boulton, 2014). As such, the promotion of a neoliberalist agenda within PBM meetings could potentially feed into the illusion of choice identified by Crossley (2007). A focus on personal agency holds the woman responsible for her birth experience and she may have feelings of failure if her birth plan is not followed. To a certain extent PBM meetings address this somewhat by inviting health professionals to attend and encouraging women to share a range of authentic birth stories. This allows women to consider the ways in which the wider contexts shape birthing experiences. A stronger relationship between PBM groups and their NHS trust could potentially further contextualise birth stories through meaningful discussion between pregnant women and their healthcare providers. Findings from the wider research project have worked towards this goal by disseminating information to practitioners (Authors, 2016).

Whilst the PBM had a positive impact upon the women interviewed, their scope to become more transformative and reach out to working class women may centre on resisting neoliberalist discourses of choice. A focus on choice and personal responsibility may alienate working class women who traditionally have limited power and opportunity to exercise 'free' choice. Working class women may not relate to a discourse of personal agency and potentially view it as blaming bad birth experiences upon women who made the wrong decisions. This suggests that further research is needed to explore the experiences of women from disadvantaged groups in order to gain more insight into the kinds of support they would find useful. 


\section{References}

Ayers, S., Eagle, A. \& Waring, H. (2006). The effects of childbirth-related posttraumatic stress disorder on women and their relationships: A qualitative study. Psychology, Health \& Medicine 11(4) pp. 389-398 DOI: 10.1080/1354850060070840 Bailham, D., \& Joseph, S. (2003). Post-traumatic stress following childbirth: a review of the emerging literature and directions for research and practice. Psychology, Health and Medicine 8, pp. 159-168.

Barker, C \& Galasinski, D. (2001). Cultural Studies and Discourse Analysis: A dialogue on language and identity. London: Sage Publication.

Beck, U. (1992) The risk society. Towards a new modernity. London: Sage.

Beckett, K. (2005). Choosing caesarean: Feminism and the politics of childbirth in the United States. Feminist Theory 6(3): 251-275.

Birth Trauma Association (2018). http://www.birthtraumaassociation.org.uk/mediainformation

Braun, V. \& Clarke, V. (2006) Using thematic analysis in psychology. Qualitative Research in Psychology, 3(2), 77-101.

British Psychological Society (2009.) Code of Ethics and Conduct. Leicester: British Psychological Society. 
Brubaker S. J., \& Dillaway H.E. (2009.) Medicalization, natural childbirth and birthing. Sociology Compass 3(1): 31-48.

Budds, K., Locke, A. \& Burr, V. (2016). “For some people it isn't a choice, it's just how it happens": Accounts of 'delayed' motherhood among middle-class women in the UK. Feminism and Psychology, 26 (2), 170-187

Cheyney, M.J. (2008). Homebirth as systems-challenging praxis: Knowledge, power, and intimacy in the birthplace. Qualitative Health Research 18(2): 254-267.

Cipolletta, S., Sperotto, A. (2012). From the hospital organization to the childbirth practice: Italian women's experiences. Journal of Reproductive and Infant Psychology, 30, 326-336.

Crossley, M. (2007). Childbirth, Complications and the Illusion of 'Choice': A Case Study. Feminism and Psychology, 17 (4), 543-563

Davies, B., \& Harré, R. (1990). Positioning: The discursive production of selves. Journal for the Theory of Social Behaviour, 20 (1), 43-63.

Elston, M. A. (1991). The politics of profession power: Medicine in a changing health service. Chapter in J. Gabe, M. Calnan and M. Bury (eds) The Sociology of the Health Service. London: Routledge.

Foucault, M. (2008). The Birth of Biopolitics: Lectures at the College de France, 19781979. Translated by Graham Burchell. New York: Palgrave Macmillan.

Gergen, K. (2015). An invitation to Social Construction(2 ${ }^{\text {nd }}$ Edition). London: Sage 
Gillies, V. (2007). Marginalised Mothers: Exploring working-class experiences of parenting. London: Routledge.

Graham, L. J. (2005). Discourse analysis and the critical use of Foucault. Retrieved from http://eprints.qut.edu.au/2689/1/2689.pdf

Green, J.M., Coupland, V.A.,\& Kitzinger, J.V., (1990).Expectations, experiences, and psychological outcomes of childbirth: a prospective study of 825 women. Birth 17, pp. 15-24.

Gross H. and Pattison H. (2007) Sanctioning Pregnancy: A Psychological Perspective on the Paradoxes and Culture of Research. East Sussex : Routledge.

Halldorsdottir, S., \& Karlsdottir, S.I., (1996). Empowerment or discouragement: women's experience of caring and uncaring encounters during childbirth. Health Care Women International 17, pp. 361-379.

Hook, D. (2001). Discourse, Knowledge, Materiality, History: Foucault and discourse analysis, London: LSE Research Online. Retrieved from

\section{http://eprints.Ise.ac.uk/archive/956}

Kukla, R. (2005). Mass hysteria: Medicine, culture, and mothers' bodies. Oxford: Rowman \& Littlefield Publishers, Inc.

Locke, A., \& Budds, K. (2013). "We thought if it's going to take two years then we need to start that now": Age, infertility risk, and the timing of pregnancy in older first-time mothers. Health, Risk \& Society, 6-7, 525-542. 
Lundgren, I., (2005). Swedish women's experience of childbirth 2 years after birth. Midwifery 21, pp. 346-354.

Lupton D (2012) 'Precious Cargo': Foetal subjects, risk and reproductive citizenship. Critical Public Health 22(3): 329-340.

Malacrida, C. \& Boulton, T. (2014). The best laid plans? Women's choices, expectations and experiences in childbirth. Health, 18 (1), 41-59.

Oksala, J. (2013). Neoliberalism and Biopolitical Governmentality (p.53-73), in Nilsson, J., \& Wallenstein, S. V., 2013. Foucault, Biopolitics and Governmentality. Stockholm: Södertörn Academic Studies 54

PBM (2018) http://www.positivebirthmovement.org/our-manifesto.html

Prilleltensky, I., \& Nelson, G. (1997). 'Community Psychology: Reclaiming Social Justice.' In D. Fox and I. Prilleltensky (eds), Critical Psychology: An Introduction (16684). London: Sage

Rappaport, J., \& Stewart, E. (1997). A critical look at critical psychology: Elaborating the questions. In D. Fox and I. Prilleltensky (eds), Critical Psychology: An Introduction pp. 501-17. London: Sage.

Read, J. (2009). A Genealogy of Homo-Economicus: Foucault, Neoliberalism and the Production of Subjectivity in S. Binkley and J. Capetillo-Ponce, A Foucault for the $21^{\text {st }}$ century: Governmentality, Biopolitics and Discipline in the new millennium. Newcastle upon Tyne: Cambridge Scholars Publishing 
Simkin, P. (1992). Just another day in a woman's life? Part II: Nature and consistency of women's long-term memories of their first birth experiences. Birth, 19, pp. 64-81.

Smith, J. A. (1994). 'Towards reflexive practice: Engaging participants as co-

researchers or co-analysts in psychological inquiry'. Journal of Community and Applied Social Psychology, 4, 253-60. 